\title{
Stable Agrobacterium-Mediated Transformation of Maritime Pine Based on Kanamycin Selection
}

\author{
José M. Alvarez ${ }^{1,2}$ and Ricardo J. Ordás ${ }^{1,3}$ \\ ${ }^{1}$ Laboratorio de Biotecnología Agroforestal, Escuela Politécnica de Mieres, Universidad de Oviedo, Calle Gonzalo Gutiérrez Quirós, \\ 33600 Mieres, Spain \\ ${ }^{2}$ Department of Plant Biology and Forest Genetics, Uppsala BioCenter, Swedish University of Agricultural Sciences, P.O. Box 7080, \\ 75007 Uppsala, Sweden \\ ${ }^{3}$ Área de Fisiología Vegetal, Departamento BOS, Universidad de Oviedo, Calle Catedrático Rodrigo Uría s/n, 33071 Oviedo, Spain \\ Correspondence should be addressed to José M. Alvarez; alvarezmanuel@uniovi.es
}

Received 22 August 2013; Accepted 29 September 2013

Academic Editors: S. Tan and D. Ustek

Copyright ( 2013 J. M. Alvarez and R. J. Ordás. This is an open access article distributed under the Creative Commons Attribution License, which permits unrestricted use, distribution, and reproduction in any medium, provided the original work is properly cited.

\begin{abstract}
An efficient transformation protocol based on kanamycin selection was developed for Agrobacterium-mediated transformation of maritime pine embryonal masses. The binary vector pBINUbiGUSint, which contained neomycin phosphotransferase II (nptII) as a selectable marker gene and $\beta$-glucuronidase (uidA) as a reporter gene, was used for transformation studies. Different factors, such as embryogenic line, bacterial strain, bacterial concentration, and coculture duration, were examined and optimized. For selection of transformants, $15 \mathrm{mgL}^{-1}$ kanamycin was used. The highest transformation efficiency (11.4 events per gram of fresh mass) was achieved when a vigorously growing embryonal mass (embryogenic line L01) was cocultivated with Agrobacterium strain AGL1 at the optical density $\left(\mathrm{OD}_{600 \mathrm{~nm}}\right)$ of 0.3 for $72 \mathrm{~h}$. Evidence of the stable transgene integration was obtained by polymerase chain reaction for the $n p t I I$ and uidA genes and expression of the uidA gene. Maturation capacity of the transgenic lines was negatively affected by the transformation process. Induction of axillary shoots by preculturing the embryos with benzyladenine allowed overcoming the low maturation rates of some transformed lines. The transgenic embryos were germinated and the axillar shoots were rooted. Transgenic plants were transferred to potting substrate showing normal growth.
\end{abstract}

\section{Introduction}

Maritime pine (Pinus pinaster Ait.) is the most widely planted softwood species in France, Spain, and Portugal. It has also been widely cultivated in nonnative areas such as Australia, South Africa, South America, and New Zealand forming part of reforestation programmes. Biotechnological approaches for the improvement of maritime pine, such as in vitro propagation based on somatic embryogenesis (SE), offer new opportunities in the field of propagation and genetic engineering [1]. Genetic transformation of embryonal masses (EM) provides the potential to allow gene function analysis or to transfer specific traits into selected genotypes without affecting their desirable genetic background, and when associated with conventional breeding, it may provide a powerful tool for rapid increase in yield and wood quality. Transgenic studies aimed at shortening the juvenile phase, studying phytoremediation, altering the lignin biosynthesis pathway, and increasing cellulose accumulation have been carried out also in other tree species [2-4].

Somatic embryogenesis from immature zygotic embryos has been the most commonly used method for regeneration of transformed conifer plants. Embryonal masses provide a source of dividing cells that were recognized as the most competent cells for genetic transformation [5], and it is almost an unlimited source of starting material. Embryogenic cultures are amenable to Agrobacterium-mediated or biolistic transformation, and somatic embryos could be initiated from single cells [6]. Another advantage of SE is the possibility of cryopreserving the obtained transformed lines.

Agrobacterium-mediated transformation has become the preferred method since it has significant advantages over 
direct DNA delivery (e.g., biolistic), such as more predictable transgene integration patterns, and the introduction of one or a few copies of genes into the plant genome decreasing the probability of gene silencing [7], high coexpression of introduced genes, less fragmentation of the transgene [8]. In addition, Agrobacterium was a much more efficient transformation tool in compatible plant species compared with the biolistic protocol [9]. The Agrobacterium-mediated method has been widely applied to different tissues of several pine species. However, it has been shown that transformation efficiency was strongly affected by EM genotype and age, the $A$. tumefaciens strain, the cocultivation protocol, control of bacterial growth with bactericides, and selection procedure [5].

An efficient transformation procedure is a prerequisite for functional genomic studies, such as studying metabolic pathways or validation of candidate genes. Most of these studies regarding conifers are being carried out in Arabidopsis. However, the differences between two evolutionary distant genera, Arabidopsis (angiosperms) and Pinus (gymnosperms), call for a specific analysis in the latter [10]. Thus, additional research is needed to further refine Agrobacterium-mediated protocols in order to broaden the range of transformable genotypes, selective agents, or Agrobacterium strains. The selective genes involved in stable transformation studies are (1) neomycin phosphotransferase II (nptII) that confers resistance to kanamycin, (2) hygromycin phosphotransferase (hpt) that confers resistance to hygromycin, and (3) the herbicideresistant gene bar that confers resistance to phosphinothricin. Embryonal masses from $P$. pinaster were previously used for genetic transformation of French [11] and Portuguese [12] genotypes. The two reports described hygromycin selection, but transgenic plants were obtained only in French genotypes. More recently, Trontin et al. [5] mentioned the use of herbicide resistance selection with similar or higher transformation efficiencies than hygromycin. Although kanamycin is the most widely used antibiotic for plant transformation, few reports about the successful use of kanamycin in maritime pine have been made $[10,13]$. In conifers, kanamycin selection seems to be a good choice for zygotic embryos of Picea glauca [14], Larix kaempferi X L. decidua [15], Pinus taeda [16], and Pinus strobus [17] and somatic embryos of Picea abies [18], Pinus strobus [19, 20], and Pinus radiata [21]. However, it was problematic in cotyledons of Pinus radiata [22], P. pinea [23], and $P$ nigra [24]. The sensitivity of a particular tissue to kanamycin is a key element in the development of any new transformation system in which a kanamycin resistance gene is used [23].

The objective of the present study was to develop a transformation protocol for Pinus pinaster EM based on kanamycin selection of transformation events allowing the direct use of binary plasmids harboring the nptII gene developed for the study of gene expression. In this work, the genetic transformation of 5 maritime pine embryogenic lines (Spanish genotypes) through cocultivation with A. tumefaciens was studied and the sensitivity to kanamycin is presented and compared with hygromycin sensitivity. The analysis of several factors such as the A. tumefaciens strain, bacterial concentration, and duration of coculture has improved the transformation efficiency of this species. In our laboratory, the protocol presented in this study is being successfully applied to produce transgenic plants and to study genetic regulation in conifers $[10,13]$. In addition, axillary shoots were induced by benzyladenine [25] in the transgenic embryos to overcome the low maturation rates of some transformed lines.

\section{Materials and Methods}

2.1. Plant Material and Culture Conditions. Embryogenic cultures of maritime pine were initiated from Spanish trees located in Asturias in 2009. Immature zygotic embryos were treated according to Lelu-Walter et al. [26] with some modifications; Westvaco WV5 medium [27] supplemented with $1 \mathrm{gL}^{-1}$ casein hydrolysate, $0.5 \mathrm{gL}^{-1} \mathrm{~L}$-glutamine, $30 \mathrm{gL}^{-1}$ sucrose, $4.4 \mu \mathrm{M}$ benzyladenine (BA), $9 \mu \mathrm{M}$ 2,4-dichlorophenoxyacetic acid (2,4-D), $4 \mathrm{gL}^{-1}$ Gelrite (all purchased from Duchefa, Haarlem, The Netherlands), and pH 5.7 was used for initiation. Proliferating EM were subcultured on the same maintenance medium with the concentration of plant growth regulators (PGR) reduced to one-half. Embryogenic lines obtained were cryopreserved according to Alvarez et al. [28] when they were 3 months old. Five lines (L01, L05, L13, L15, and L26) characterized by high somatic embryo maturation yields were recovered from cryopreserved stock and used for transformation experiments.

2.2. Embryogenic Line Sensitivity to Selective Agents. The selective agents kanamycin and hygromycin (Duchefa) were tested. Five $\mathrm{mL}$ of a fine suspension of EM from each line assayed $\left(100 \mathrm{mg} \mathrm{mL}^{-1}\right)$ was poured onto a filter paper disc (Whatman number 2, $7 \mathrm{~mm}$ diameter) and drained by a lowpressure pulse in a Buchner funnel. The filter paper disc was placed on maintenance medium (without casein hydrolysate) supplemented with $500 \mathrm{mgL}^{-1}$ cefotaxime (bactericide agent; control) or with $500 \mathrm{mgL}^{-1}$ cefotaxime plus the selective agent at $1,5,10,15,20$, or $25 \mathrm{mgL}^{-1}$. The filter paper discs were subcultured onto fresh medium every 2 weeks for 3 subcultures. The relative fresh weight increment was calculated at the end of the treatment.

\subsection{Agrobacterium Strains and Transformation Protocol.} Three disarmed Agrobacterium tumefaciens strains were used in the transformation experiments: EHA105 [29], LBA4404 [30], and AGL1 [31]. These strains harbored the binary vector pBINUbiGUSint (see Resource 1 in Supplementary Material available online at http://dx.doi.org/10.1155/2013/681792, [32]) developed in our laboratory, a derivative of pBIN19 [33], carrying the neomycin phosphotransferase II (nptII) and the $\beta$-glucuronidase (uidA; GUS) genes driven by the nopaline synthase promoter (NOS-P) and the promoter of the $u b i 1$ gene of maize polyubiquitin [34], respectively. Both genes carried the NOS-pA terminator. The uidA gene used in these experiments contained the PIV2 intron of the ST-L1 gene from Solanum tuberosum within its coding sequence (uidAint), thereby preventing its expression in Agrobacterium [35]. Bacteria at optical densities $\left(\mathrm{OD}_{600 \mathrm{~nm}}\right)$ of $0.3,0.15$, and 0.075 were cocultured with the EM for 48 and $72 \mathrm{~h}$. 
The inoculation and cocultivation procedure was based on the protocol of Levée et al. [19] with some modifications. Bacterial cultures were started from glycerol stocks on solid YEP medium [36] containing $50 \mathrm{mgL}^{-1}$ rifampicin (chromosomal selection) and $50 \mathrm{mgL}^{-1}$ kanamycin (pBINUbiGUSint selection) for $48 \mathrm{~h}$ at $27^{\circ} \mathrm{C}$. One colony was grown in $2 \mathrm{~mL}$ liquid YEP medium with $50 \mathrm{mgL}^{-1}$ kanamycin overnight at $27^{\circ} \mathrm{C}$ and $150 \mathrm{rpm}$ and then diluted $1: 100$ in the same medium and grown for $16 \mathrm{~h}$. The suspension was centrifuged at 4,000 rpm for $10 \mathrm{~min}$ and the pellet resuspended in liquid WV5 medium to the desired optical densities $\left(\mathrm{OD}_{600 \mathrm{~nm}}\right)$. Then, the necessary amount of EM to obtain a suspension of $100 \mathrm{mg} \mathrm{mL}^{-1}$ was added and disaggregated by vortex pulses. Acetosyringone $(100 \mu \mathrm{M})$ was added according to López et al. [24]. The suspension was poured onto filter paper $(5 \mathrm{~mL}$ per $7 \mathrm{~cm}$ diameter filter disc) and drained using a low-pressure pulse in a Buchner funnel. The filter discs were placed on cocultivation medium (maintenance medium without casein hydrolysate) in a $90 \mathrm{~mm}$ diameter $\times 14 \mathrm{~mm}$ depth Petri dish sealed with paraffin film (Parafilm), in darkness at $23^{\circ} \mathrm{C}$ for 48 or $72 \mathrm{~h}$. After cocultivation, paper discs were washed four times with $10 \mathrm{~mL}$ WV5 liquid medium in a Buchner funnel, drained with low-pressure pulse, and placed on decontamination medium (cocultivation medium with $500 \mathrm{mgL}^{-1}$ cefotaxime). After 1 week, the paper discs were transferred onto selective medium (decontamination medium with $15 \mathrm{mgL}^{-1}$ kanamycin) and subcultured every 2 weeks. Each embryogenic event growing on selective medium was considered as a putative independent transformation event and was isolated and grown on selective medium for at least six more subcultures.

The number of transformation events per gram of fresh mass for each Agrobacterium strain was recorded after 120 days for the embryogenic line L01. Ten independent putative kanamycin-resistant events from line L01 were selected for molecular and histochemical assays. These lines were cryopreserved and subjected to maturation and germination.

2.4. Maturation and Conversion into Plants. Maturation and germination were based on Alvarez et al. [25]. For maturation, $150 \mathrm{mg}$ EM from each transformed line was disaggregated in $2 \mathrm{~mL}$ sterile water. The suspension was poured onto a piece of autoclaved filter paper disc, drained using a low-pressure pulse in a Buchner funnel, and placed on WV5 medium supplemented with $550 \mathrm{mgL}^{-1} \mathrm{~L}$-glutamine (Duchefa), $525 \mathrm{mgL}^{-1}$ L-asparagine (Duchefa), $175 \mathrm{mgL}^{-1}$ L-arginine (Duchefa), $19.75 \mathrm{mgL}^{-1}$ L-citrulline (Sigma), $19 \mathrm{mgL}^{-1}$ L-ornithine (Duchefa), $13.75 \mathrm{mgL}^{-1}$ L-lysine (Duchefa), $10 \mathrm{mgL}^{-1}$ L-alanine (Duchefa), $8.75 \mathrm{mgL}^{-1} \mathrm{~L}$ proline (Duchefa), $60 \mathrm{gL}^{-1}$ sucrose, and $9 \mathrm{gL}^{-1}$ Gelrite. After 1 week, the paper disc was transferred onto the same medium supplemented with $80 \mu \mathrm{M}$ abscisic acid (ABA) (Duchefa). Amino acids and ABA were filter-sterilized and added after autoclaving. Cultures were subcultured on fresh medium every 3 weeks for 3 months.

Mature somatic embryos of each transformed line were isolated and placed on PGR-free WV5 medium supplemented with $30 \mathrm{gL}^{-1}$ sucrose and $4 \mathrm{gL}^{-1}$ Gelrite until radicle elongation and bud breaking were evident. In order to overcome the problems associated with low maturation rates in some transformed lines, axillary shoots were induced in mature somatic embryos by preculturing with BA $(10 \mu \mathrm{M})$ for 7 days before transferring to germination medium [25]. Axillary shoots were isolated and rooted according to Álvarez et al. [37]. Then, plants from germinated embryos and rooted shoots were placed in a peat-vermiculite substrate $(1: 1 \mathrm{v} / \mathrm{v})$ and grown at $95 \%$ relative humidity $(\mathrm{RH})$ controlled by a fog system. RH was reduced by $5 \%$ every 3 days. After approximately 3 weeks, the plants were transferred to ambient humidity conditions in the greenhouse.

2.5. Molecular Analysis. Molecular analysis was performed on 10 independent kanamycin-resistant embryogenic lines. The putative transgenic events were PCR-tested for the nptII, uidA, and $v i r G$ genes. A noninoculated line and the AGL1 strain carrying the pBINUbiGUSint plasmid were used as negative and positive controls, respectively. Genomic DNA was extracted using the NucleoSpin Plant II Kit (MachereyNagel, Germany). The amplification was performed in a Biometra T-Gradient Thermoblock thermocycler with the Kapa Taq PCR kit (Kapa Biosystems Inc., Woburn, MA, USA). Approximately $10 \mathrm{ng}$ template was amplified in $10 \mu \mathrm{L}$ reactions using the following PCR protocol: $95^{\circ} \mathrm{C} 5 \mathrm{~min} ; 35$ cycles of $95^{\circ} \mathrm{C} 30 \mathrm{~s}, 60^{\circ} \mathrm{C} 30 \mathrm{~s}$, and $72^{\circ} \mathrm{C} 1 \mathrm{~min} ; 72^{\circ} \mathrm{C} 5 \mathrm{~min}$. Primers used are listed in Online Resource 2. Five transgenic plants (one-year-old) from germinated embryos and five rooted shoots were also PCR-tested for the nptII, uidA, and $\operatorname{vir} G$ genes as above.

Transgene copy number was estimated by real-time PCR [38] using the comparative $\mathrm{Ct}$ method [39]. The analysis was performed on an ABI PRISM 7900HT instrument (Applied Biosystems Inc.) using the Fast SYBR Green Master Mix (Applied Biosystems Inc.). Reaction efficiency and Ct were calculated using the LinRegPCR software [40]. Approximately 10 ng DNA was amplified per $10 \mu \mathrm{L}$ reaction using the following protocol: $95^{\circ} \mathrm{C} 20 \mathrm{~s}, 45$ cycles of $95^{\circ} \mathrm{C} 1 \mathrm{~s}$, and $60^{\circ} \mathrm{C}$ 20 s. The Pips-C61 gene (GenBank AJ490522), reported as a single-copy gene in the P. pinaster genome [41], was selected as endogenous control. Real-time PCR specificity was assessed using negative controls (no template), a melting curve analysis, and by gel electrophoresis. Three biological and two technical replicates were used per analysis. Primers (listed in Online Resource 2) were designed to amplify a fragment of the uidA (GUS) and Pips-C61 genes, both with a $60^{\circ} \mathrm{C}$ $\mathrm{Tm}$. The transgenic line $\mathrm{T} 1$ showed the lowest $\Delta \mathrm{Ct}, \Delta \mathrm{Ct}$ being the difference between $\mathrm{Ct}$ for transgene and $\mathrm{Ct}$ for endogenous control $\left(\mathrm{Ct}_{\mathrm{GUS}}-\mathrm{Ct}_{\mathrm{Pips-C61}}\right)$, and was set as calibrator. The copy number was calculated as $E^{-\Delta \Delta \mathrm{Ct}}$, where $E=\mathrm{PCR}$ efficiency and $\Delta \Delta \mathrm{Ct}=\Delta \mathrm{Ct}$ sample $-\Delta \mathrm{Ct}$ calibrator. The difference $(\Delta \mathrm{Ct})$ between the transgene $\mathrm{Ct}$ and endogenous control $\mathrm{Ct}$ was constant, independent of the amount of chromosomal DNA when PCR efficiencies of endogenous control and transgene were the same [38]. The transgenic T1 line was confirmed as harboring a single copy by Southern blot analysis (not shown). 
2.6. $\beta$-Glucuronidase Assay during Embryo Development. $\beta$ Glucuronidase (GUS) activity was analysed fluorometrically and histochemically, both according to Jefferson et al. [42]. The assays were carried out on 10 kanamycin-resistant independent embryogenic lines. The fluorometric assay was performed on a TKO 100 Fluorometer (Hoefer Inc., MA, USA). Approximately $100 \mathrm{mg}$ proliferating EM from each line were used. GUS activity is expressed as picomoles of methylumbelliferone (MU) per minute and per milligram of total protein. Total protein was quantified by the Bradford method [43]. Three independent assays were performed and samples were analysed in triplicate. The histochemical GUS assay was performed 15, 45, and 90 days after transfer onto maturation medium and in young needles from the transgenic plants. Blue colour development was evaluated after $16 \mathrm{~h}$ incubation at $37^{\circ} \mathrm{C}$ in GUS solution.

2.7. Data Analysis. For kanamycin sensitivity tests, the samples were weighed at day 0 and after three subcultures. Relative fresh weight increment was calculated as follows: $\Delta \mathrm{FW}_{3}=$ $\left(\mathrm{FW}_{3}-\mathrm{FW}_{0}\right) / \mathrm{FW}_{0}$. $\mathrm{A} \Delta \mathrm{FW}_{3}<2$ was considered as growth inhibition.

An evaluation of maturation was determined by counting the number of mature somatic embryos per gram fresh tissue after 3 months on maturation medium. A mature somatic embryo was a white to yellowish embryo on which cotyledons are visible. This corresponds to stage 3 of somatic embryo development in P. pinaster as defined by Ramarosandratana et al. [44].

Data are presented as mean \pm standard error of three independent replicates per experiment. Each experiment was performed at least twice at different times and assayed using a completely randomized design. The statistical analysis of categorical variables was carried out with the $\chi^{2}$ test for overall and pairwise comparisons, except where indicated. Quantitative data were analyzed by analysis of variance (ANOVA) using the Holm-Sidak test for post hoc comparisons. Differences were considered significant at the 5 percent level. All statistical tests were performed with SigmaPlot v11.0 (Systat Software, Inc., San Jose, CA, USA).

\section{Results}

3.1. Embryogenic Line Sensitivity to the Selective Agents. To determine the sensitivity of embryogenic cultures to the selective agents, untransformed lines (L01, L05, L13, L15, and L26) were cultured on maintenance medium supplemented with $500 \mathrm{mgL}^{-1}$ cefotaxime plus the selective agent at different concentrations. The selective agents tested inhibited the growth of the EM. Kanamycin and hygromycin showed a similar behaviour since a concentration of $15 \mathrm{mgL}^{-1}$ was enough to inhibit growth in all lines tested (Figure 1), and after three subcultures, the tissue necrotized (Online Resource 3).

\subsection{Agrobacterium Strains and Transformation Protocol.} The susceptibility of maritime pine embryogenic cultures to infection with three different $A$. tumefaciens strains (EHA105, LBA4404, and AGL1) harboring the pBINUbiGUSint

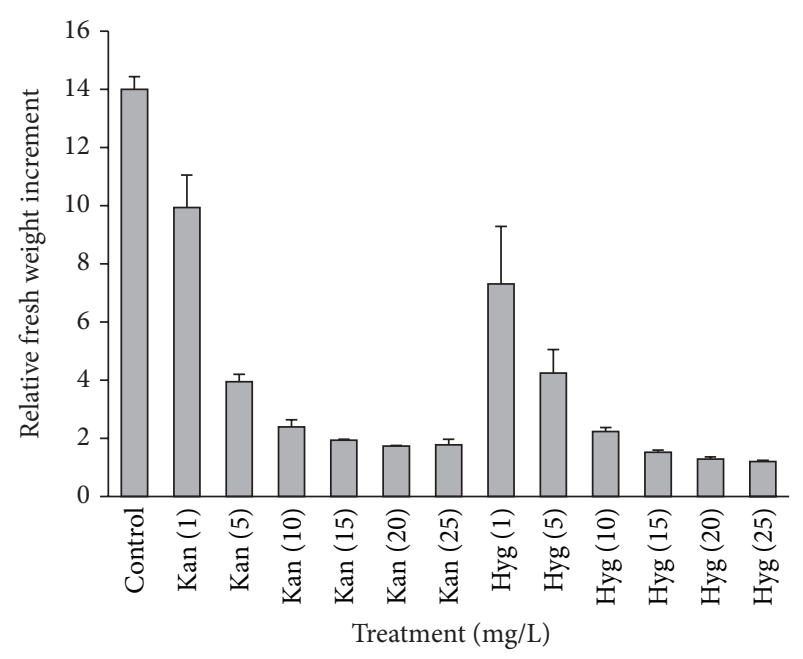

FIGURE 1: EM sensitivity to the selective agents. Kan: kanamycin, Hyg: hygromycin. Data were collected after 3 subcultures (6 weeks) and the values for the 5 embryogenic lines were averaged.

plasmid was also studied. Cefotaxime was successfully used to suppress the growth of the three Agrobacterium strains tested. No transformation events were obtained for lines L13, L15, and L26. Line L05 showed transformation events only with the AGL1 strain at $\mathrm{OD}_{600 \mathrm{~nm}} 0.3$ and a $48 \mathrm{~h}$ cocultivation (6.3 \pm 0.7 transformation events per gram of fresh mass). Line L01 showed transformation events with AGL1 and EHA105 strains, but none were obtained with the LBA4404 strain. After 120 days of culture, the number of transformation events per gram of fresh mass varied significantly, depending on the strain used (Table 1).

About 2 months after transformation, white proliferating masses (Online Resource 4) were detected, and these were subsequently transferred to fresh selective medium. After a further 3 months of culture on selective medium, the proliferating EM were considered to be putatively transgenic clones and were selected for molecular and histochemical analysis.

3.3. Maturation and Conversion into Plants. For maturation, kanamycin and cefotaxime were removed. No Agrobacterium regrowth was observed. Mature embryos were obtained from 6 out of 10 transgenic lines (Figure 2). The number of mature embryos showed a high variability among lines, on average with $13.8 \pm 3.4$ mature embryos per gram of fresh mass. This value was significantly lower than $231.9 \pm 7.1$ mature embryos per gram of fresh mass in the untransformed line L01 at the same age. No correlations were observed among maturation capacity, number of T-DNA insertions, and GUS activity (Figure 2). Transgenic lines that showed mature embryos were cryopreserved and recovered. No reduction in maturation capacity was observed after cryopreservation.

After 1 month on germination medium, $68.2 \%$ of embryos showed radicle elongation and bud-break. These were transferred to peat-vermiculite substrate and plant conversion was $71.4 \%$.

No significant differences on germination or acclimatization percentages were observed when the transgenic embryos 
TABLE 1: Number of transformation events per gram of fresh mass in line L01 after 120 days on selective medium. LBA4404 strain did not show transformation events.

\begin{tabular}{lccc}
\hline Strain & Cocultivation (hours) & OD $_{600 \mathrm{~nm}}$ & Transformation events \\
\hline AGL1 & 48 & 0.075 & $1.1 \pm 0.2^{\mathrm{e}}$ \\
AGL1 & 48 & 0.15 & $4.4 \pm 0.7^{\mathrm{cd}}$ \\
AGL1 & 48 & 0.3 & $7.7 \pm 0.9^{\mathrm{bc}}$ \\
AGL1 & 72 & 0.075 & $2.1 \pm 0.6^{\mathrm{de}}$ \\
AGL1 & 72 & 0.15 & $10.3 \pm 1.2^{\mathrm{ab}}$ \\
AGL1 & 72 & 0.3 & $11.4 \pm 1.6^{\mathrm{a}}$ \\
EHA105 & 48 & 0.075 & $0.0 \pm 0.0^{\mathrm{e}}$ \\
EHA105 & 48 & 0.15 & $0.0 \pm 0.0^{\mathrm{e}}$ \\
EHA105 & 48 & 0.3 & $0.7 \pm 0.2^{\mathrm{e}}$ \\
EHA105 & 72 & 0.075 & $0.0 \pm 0.0^{\mathrm{e}}$ \\
EHA105 & 72 & 0.15 & $0.7 \pm 0.4^{\mathrm{e}}$ \\
EHA105 & 72 & 0.3 & $0.9 \pm 0.3^{\mathrm{e}}$ \\
\hline
\end{tabular}

The data correspond to the mean values \pm standard error in three independent experiments $(n=3)$. Different letters represent significant differences (Holm-Sidak, $\alpha=0.05$ ).

were treated with BA before transferring to germination medium compared with nontreated embryos. In addition, various axillary shoots per plantlet (5-6) were obtained after 3 months of culture on germination medium. The lateral shoots were isolated and rooted (85\%). No plagiotropic growth was observed and the plants showed a well-developed root system capable of sustaining further shoot outgrowth.

3.4. Molecular Analysis. Ten putative transgenic lines resistant to kanamycin were tested by PCR to detect the nptII and uidA genes (included in the T-DNA) and the virG gene (to detect bacterial contamination). All of the lines were PCR-positive for both nptII and uidA genes, so no escapes were detected. The virG gene was only amplified in the positive control (AGL1 pBINUbiGUSint). No amplification was detected in the negative control (nontransformed L01 line) (Online Resource 5). The five transgenic plants (one-yearold) from germinated embryos and the five rooted shoots tested for the nptII and uidA genes were PCR-positive. No amplification was detected for the virG gene (Online Resource 6). Copy number estimation by the comparative $\mathrm{Ct}$ method showed one copy in five lines, two copies in two lines and three or more copies in three lines (Figure 2).

3.5. $\beta$-Glucuronidase Assay during Embryo Development. The presence of GUS activity in the EM and embryos harboring the uidA gene was investigated by histochemical assay. All transgenic lines were positive during EM proliferation and maturation. GUS staining in mature embryos (stage 3) was often located in the hypocotyl. Young needles also showed GUS staining. No chimeric tissue or escapes were observed (Figure 3).

The GUS fluorometric assay revealed significant differences in activity levels (from $550.0 \pm 22.1$ to $17,831.2 \pm$ 4,501.3 pmol MU min ${ }^{-1} \mathrm{mg}^{-1}$ of total protein) for the 10 transgenic lines during EM proliferation (Figure 2). No significant

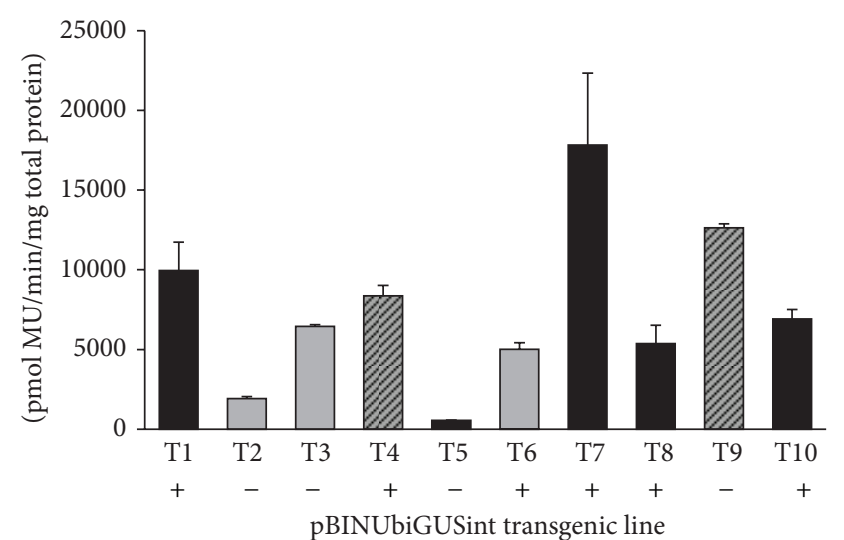

FIGURE 2: Fluorometric assay of 10 kanamycin-resistant lines. Different bar fills indicate transgene copy number: 1 copy (solid black), 2 copies (striped grey), and 3 or more copies (solid grey). The presence $(+)$ or absence $(-)$ of maturation is depicted under each transgenic line.

correlations were found between GUS activity levels and transgene copy number. Both the highest and the lowest expression levels were found in single-copy lines.

\section{Discussion}

Somatic embryogenesis in $P$. pinaster has been improved in recent years $[1,26,45]$ providing a source of competent cells for genetic transformation. Genetic engineering can facilitate the introduction of economically important genes that may otherwise be difficult to integrate into elite genotypes [5], especially in forest tree species with long reproductive periods where conventional breeding can pose a long-term challenge. Furthermore, genetic transformation is a very attractive alternative for studying candidate gene function. To produce stably transformed plants, the desired DNA has to be introduced into plant cells and integrated into the cell genome. These transgenic cells must then be selected, multiplied, and finally regenerated into a plant. Therefore, development of efficient gene delivery systems based on efficient in vitro plant regeneration protocols is a prerequisite for the application of genetic transformation in any species.

In this work, we report obtaining transformed plantlets from $P$. pinaster EM based on kanamycin selection. Various factors influencing the efficiency of T-DNA delivery into maritime pine embryogenic cells via A. tumefaciens were evaluated. Cefotaxime, a decontamination agent used to inhibit Agrobacterium growth following infection [23], was successfully used to suppress the growth of the three Agrobacterium strains tested. Explants showed vigorous growth after 6 weeks of culture in the presence of cefotaxime (Online resource 3). AGL1 strain was confirmed as the superior tested strain and was efficiently used, thereby broadening the range of Agrobacterium strains for maritime pine transformation. AGL1 is a disarmed derivative of C58, a hypervirulent strain that has been successfully used to infect various plant species [46, 47]. 


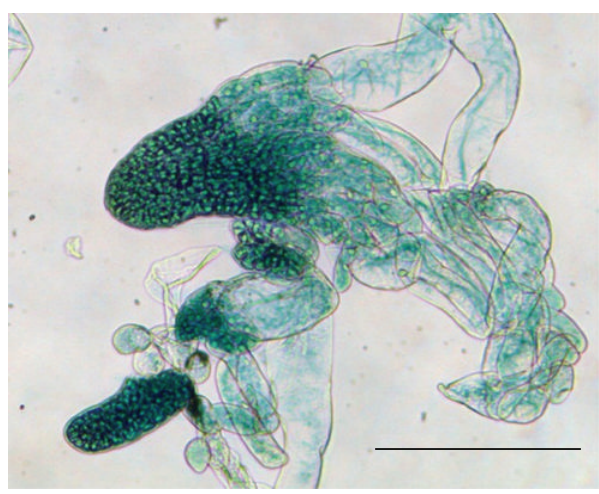

(a)

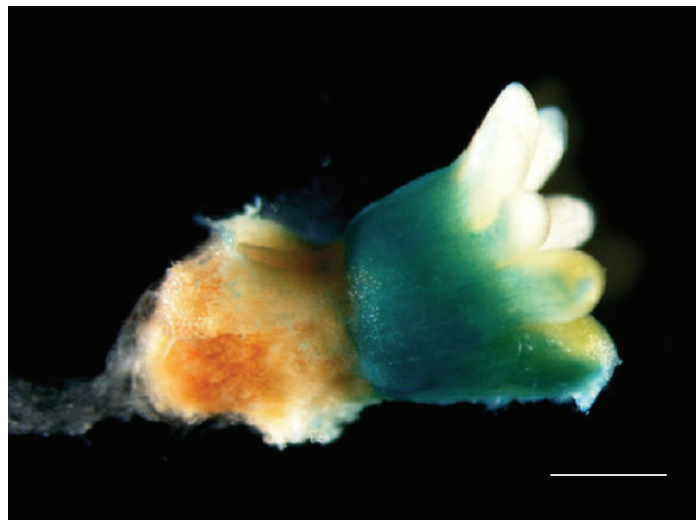

(c)

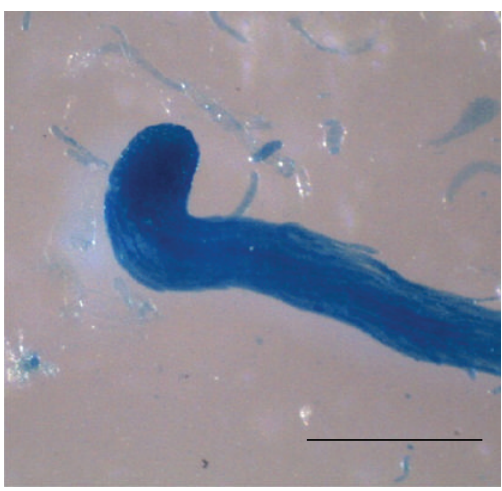

(b)

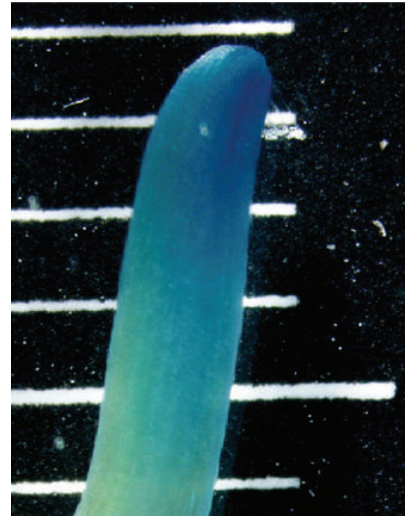

(d)

FIgURE 3: GUS activity after $16 \mathrm{~h}$ incubation in GUS solution. Embryos in different stages after 15 (stage 1 embryo; (a)), 45 (stage 2 embryo; (b)), and 90 days (stage 3 embryo; (c)) on maturation medium. Young needle (d). Bar and divisions $=1 \mathrm{~mm}$.

However, this strain has been rarely employed in pine. Trontin et al. [5] reported very low transformation frequencies with AGL1 as compared with LBA4404 and C58pMP90 strains in a French genotype. This suggests a genotypedependent compatibility. We have achieved genetic transformation in 2 out of the 5 Spanish genotypes tested, which demonstrates the known importance of genetic background on transformation efficiency [5] and stresses the need of further research to increase the range of transformable genotypes. We obtained a transformation efficiency of 11.4 events per gram of fresh mass. This result is in the range obtained in previous reports working with hygromycin resitance in French genotypes ( 0.03 to 88.29 events per gram of fresh mass [11]) or Portuguese genotypes ( 0.00 to 24.67 events per gram of fresh [12]).

pBINUbiGUSint, the kanamycin resistance-harboring binary vector used in this work, has been proven successful in woody species, such as Castanea sativa [48], Quercus suber [46], and Olea europaea [47] and in Pinus spp. transient expression studies in our laboratory [24, 32, 49]. Although kanamycin has been shown to allow morphogenesis in several species and certain species were quite resistant to kanamycin, others such as Pinus pinea and $P$. radiata $[22,23$ ] were extremely sensitive, suggesting that other selection strategies might produce better results. However, our data (Figure 1) showed a similar sensitivity of maritime pine EM to kanamycin and hygromycin.

Constructions harboring hygromycin resistance have been successfully used in maritime pine EM transformation by other authors $[11,12]$. However, obtaining transformed plantlets has been reported only once [11]. More recently, Trontin et al. [5], referring to unpublished data, suggested the use of phosphinothricin-based methods as a better alternative than hygromycin to select transgenic lines in maritime pine. Our results suggest that kanamycin selection is also a suitable alternative.

The proliferation rate of inoculated cultures was affected by the bacterial strains tested at the beginning of the culture. Although there was no early bacterial regrowth after cocultivation, the infection reduced the proliferation rate of maritime pine EM (data not shown). Delaying the transfer of the cultures to the selective medium for 7 days [19] has allowed the embryogenic cultures to recover from the inoculation stress, proliferate, and accumulate the selectable enzyme.

Maturation of transformed lines in pine has proved to be difficult $[12,50]$. A significant reduction in maturation capacity from $231.9 \pm 7.1$ in the untransformed line to an average of $13.8 \pm 3.4$ stage 3 embryos per gram of fresh mass in the transgenic lines was found. Tereso et al. [12] reported a strong reduction in maturation capacity of transformed lines since 
only 3 mature embryos were obtained from 44 lines selected with hygromycin. Trontin et al. [5] also reported a reduction in maturation yield of transformed lines using both hygromycin and phosphinothricin-based methods in the embryogenic line PN519. This loss of maturation capacity could be related to the transformation process itself, which could accelerate the loss of maturation capacity in the EM, or the mutagenic effect of T-DNA insertions [51] but further experiments are necessary for confirmation. Our results support the induction of axillary shoots by preculturing somatic embryos in the presence of BA [25] as a useful method to amplify and propagate low-maturating transgenic lines.

Expression (measured as GUS activity) of uidA gene was detected in all transformed lines of $P$. pinaster during somatic embryogenic mass proliferation and somatic embryo maturation; control cultures did not show any detectable GUS expression. Transgenic cultures proliferated in selective medium and expressed the uidA gene carrying the PIV2 intron, thereby demonstrating its functionality. High variability in GUS activity was observed between the different transformed clones. A comparison between GUS activity and transgene copy number suggests that the different level of gene expression cannot be explained by the copy number effect $[52,53]$. Therefore, other phenomena such as the position effect in the host genome [54] or other complex configurations of the integrated T-DNA $[7,55]$ should also be considered.

GUS staining was observed in all embryogenic phases, from proembryogenic masses to mature embryos and young needles. No escapes or chimeras were observed in the transgenic lines. These results support kanamycin selection as a suitable alternative for maritime pine genetic transformation.

In conclusion, a transformation method based on kanamycin selection broadens the range of selective agents reported for maritime pine EM transformation, and two new genotypes susceptible to Agrobacterium-mediated transformation are presented. The protocol is being successfully applied to produce transgenic plants and to study genetic regulation in conifers in our laboratory $[10,13]$. In previous experiments, we observed that maritime pine embryogenic cultures were susceptible to transformation with AGL1 harboring a binary vector carrying the PipsRR1 (GenBank JQ801609) promoter driving GFP:GUS expression [13]. That study was the first report on the development of a protocol to transfer foreign chimeric genes under a maritime pine promoter and one of the few reports on pines. We have also analysed the chimeric gene under the control of the PipsCLV1L (GenBank HQ377527) promoter [10]. These studies showed that an efficient transformation procedure was a prerequisite for comparative functional genomic studies between two evolutionary distant genera, such as Arabidopsis (angiosperms) and Pinus (gymnosperms).

\section{Authors' Contribution}

José M. Alvarez and Ricardo J. Ordás contributed equally to this work.

\section{Acknowledgments}

The authors thank Dr. Kevin Dalton and Dr. Ruben Alvarez for proofreading the paper and for helpful comments. This work was supported by "Ministerio de Educación y Ciencia de España” (AGL2009-12139-C02-01); "Plan de Ciencia Tecnología e Innovación del Principado de Asturias" (IB08-054 and FC10-COF10-07); and Predoctoral Grant from the "Ministerio de Educación y Ciencia de España” (FPU AP20050140) to José M. Alvarez.

\section{References}

[1] K. Klimaszewska, J. F. Trontin, M. Becwar, C. Devillard, Y. S. Park, and M. A. Lelu-Walter, "Recent progress on somatic embryogenesis of four Pinus spp," Tree Forestry Science Biotechnology, vol. 1, pp. 11-25, 2007.

[2] S. A. Merkle and J. F. Dean, "Forest tree biotechnology," Current Opinion in Biotechnology, vol. 11, no. 3, pp. 298-302, 2000.

[3] L. Peña and A. Séguin, "Recent advances in the genetic transformation of trees," Trends in Biotechnology, vol. 19, no. 12, pp. 500-506, 2001.

[4] A. Harfouche, R. Meilan, M. Kirst et al., "Accelerating the domestication of forest trees in a changing world," Trends in Plant Science, vol. 17, no. 2, pp. 64-72, 2012.

[5] J. F. Trontin, C. Walter, K. Klimaszewska, Y. S. Park, and M. A. Lelu-Walter, "Recent progress in genetic transformation of four Pinus spp," Transgenic Plant Journal, vol. 1, pp. 314-329, 2007.

[6] C.-X. Zhang, Q. Li, and L. Kong, "Induction, development and maturation of somatic embryos in Bunge's pine (Pinus bungeana Zucc. ex Endl.)," Plant Cell, Tissue and Organ Culture, vol. 91, no. 3, pp. 273-280, 2007.

[7] S. B. Gelvin, "Agrobacterium-mediated plant transformation: the biology behind the "gene-jockeying" tool," Microbiology and Molecular Biology Reviews, vol. 67, no. 1, pp. 16-37, 2003.

[8] C. Walter, S. D. Carson, M. I. Menzies, T. Richardson, and M. Carson, "Review: application of biotechnology to forestryMolecular biology of conifers," World Journal of Microbiology and Biotechnology, vol. 14, no. 3, pp. 321-330, 1998.

[9] D. Bidney, C. Scelonge, J. Martich, M. Burrus, L. Sims, and G. Huffman, "Microprojectile bombardment of plant tissues increases transformation frequency by Agrobacterium tumefaciens," Plant Molecular Biology, vol. 18, no. 2, pp. 301-313, 1992.

[10] J. M. Alvarez, M. Cortizo, N. Bueno, A. Rodríguez, and R. J. Ordás, "CLAVATA1-LIKE, a leucine-rich-repeat protein receptor kinase gene differentially expressed during adventitious caulogenesis in Pinus pinaster and Pinus pinea," Plant Cell Tissue Organ Culture, vol. 112, pp. 331-342, 2013.

[11] J.-F. Trontin, L. Harvengt, E. Garin et al., "Towards genetic engineering of maritime pine (Pinus pinaster Ait.)," Annals of Forest Science, vol. 59, no. 5-6, pp. 687-697, 2002.

[12] S. Tereso, C. Miguel, K. Zoglauer, C. Valle-Piquera, and M. M. Oliveira, "Stable Agrobacterium-mediated transformation of embryogenic tissues from Pinus pinaster Portuguese genotypes," Plant Growth Regulation, vol. 50, no. 1, pp. 57-68, 2006.

[13] J. M. Alvarez, M. Cortizo, and R. J. Ordás, "Characterization of a type-A response regulator differentially expressed during adventitious caulogenesis in Pinus pinaster," Journal of Plant Physiology, vol. 169, pp. 1807-1814, 2012.

[14] D. D. Ellis, W. R. Lazaroff, D. R. Roberts, B. S. Flinn, and D. T. Webb, "The effect of antibiotics on elongation and callus and 
bud formation from embryonic tissue of Picea glauca," Canadian Journal of Forest Research, vol. 19, pp. 1343-1346, 1989.

[15] V. Levée, M. A. Lelu, L. Jouanin, D. Cornu, and G. Pilate, “Agrobacterium tumefaciens-mediated transformation of hybrid larch (Larix kaempferi $x$ L. decidua) and transgenic plant regenerationn," Plant Cell Reports, vol. 16, no. 10, pp. 680-685, 1997.

[16] W. Tang and Y. Tian, "Transgenic loblolly pine (Pinus taeda L.) plants expressing a modified $\delta$-endotoxin gene of Bacillus thuringiensis with enhanced resistance to dendrolimus punctatus walker and crypyothelea formosicola staud," Journal of Experimental Botany, vol. 54, no. 383, pp. 835-844, 2003.

[17] W. Tang, R. J. Newton, and D. A. Weidner, "Genetic transformation and gene silencing mediated by multiple copies of a transgene in eastern white pine," Journal of Experimental Botany, vol. 58, no. 3, pp. 545-554, 2007.

[18] D. Pavingerová, J. Bříza, H. Niedermeierová, and J. Vlasák, “Stable Agrobacterium-mediated transformation of Norway spruce embryogenic tissues using somatic embryo explants," Journal of Forest Science, vol. 57, no. 7, pp. 277-280, 2011.

[19] V. Levée, E. Garin, K. Klimaszewska, and A. Séguin, "Stable genetic transformation of white pine (Pinus strobus L.) after cocultivation of embryogenic tissues with Agrobacterium tumefaciens," Molecular Breeding, vol. 5, no. 5, pp. 429-440, 1999.

[20] V. Levée and A. Séguin, "Inducible expression of the heterologous PAL2 promoter from bean in white pine (Pinus strobus) transgenic cells," Tree Physiology, vol. 21, no. 10, pp. 665-672, 2001.

[21] R. Le-Feuvre, C. Triviño, A. Sabja, M. Bernier-Cardou, M. Moynihan, and K. Klimaszewska, "Organic nitrogen composition of the tissue culture medium influences Agrobacterium tumefaciens growth and the recovery of transformed Pinus radiata embryonal masses after cocultivation," In Vitro Cellular \& Developmental Biology Plant, vol. 49, pp. 30-40, 2013.

[22] C. Walter, L. J. Grace, A. Wagner et al., "Stable transformation and regeneration of transgenic plants of Pinus radiata D. Don," Plant Cell Reports, vol. 17, no. 6-7, pp. 460-468, 1998.

[23] J. M. Humara and R. J. Ordás, "The toxicity of antibiotics and herbicides on In Vitro adventitious shoot formation on Pinus pinea L. cotyledons," In Vitro Cellular and Developmental Biology Plant, vol. 35, no. 4, pp. 339-343, 1999.

[24] M. López, J. M. Humara, R. Rodríguez, and R. J. Ordás, "Transient uidA gene expression in electroporated cotyledonary protoplasts of Pinus nigra salzmannii and in bombarded cotyledons," Canadian Journal of Forest Research, vol. 30, no. 3, pp. 448-455, 2000.

[25] J. M. Alvarez, N. Bueno, M. Cortizo, and R. J. Ordas, "Improving plantlet yield in Pinus pinaster somatic embryogenesis," Scandinavian Journal of Forest Research, vol. 28, no. 7, pp. 613-620, 2013.

[26] M.-A. Lelu-Walter, M. Bernier-Cardou, and K. Klimaszewska, "Simplified and improved somatic embryogenesis for clonal propagation of Pinus pinaster (Ait.)," Plant Cell Reports, vol. 25, no. 8, pp. 767-776, 2006.

[27] J. E. Coke, Basal Nutrient Medium For In Vitro Cultures of Loblolly Pines, Westvaco Corporation, New York, NY, USA, Patent, U.S. edition, 1996.

[28] J. M. Alvarez, M. Cortizo, and R. Ordás, "Cryopreservation of somatic embryogenic cultures of Pinus pinaster: effects on regrowth and embryo maturation," Cryo Letters, vol. 33, no. 6, pp. 476-484, 2012.
[29] E. E. Hood, S. B. Gelvin, L. S. Melchers, and A. Hoekema, "New Agrobacterium helper plasmids for gene transfer to plants," Transgenic Research, vol. 2, no. 4, pp. 208-218, 1993.

[30] A. Hoekema, P. R. Hirsch, P. J. J. Hooykaas, and R. A. Schilperoort, "A binary plant vector strategy based on separation of vir- and T-region of the Agrobacterium tumefaciens Ti-plasmid," Nature, vol. 303, no. 5913, pp. 179-180, 1983.

[31] G. R. Lazo, P. A. Stein, and R. A. Ludwig, "A DNA transformation-competent Arabidopsis genomic library in Agrobacterium," Nature Biotechnology, vol. 9, no. 10, pp. 963-967, 1991.

[32] J. M. Humara, M. S. Marín, F. Parra, and R. J. Ordás, “Improved efficiency of uidA gene transfer, in stone pine (Pinus pinea) cotyledons using a modified binary vector," Canadian Journal of Forest Research, vol. 29, no. 10, pp. 1627-1632, 1999.

[33] M. Bevan, "Binary Agrobacterium vectors for plant transformation," Nucleic Acids Research, vol. 12, no. 22, pp. 8711-8721, 1984.

[34] A. H. Christensen and P. H. Quail, "Ubiquitin promoter-based vectors for high-level expression of selectable and/or screenable marker genes in monocotyledonous plants," Transgenic Research, vol. 5, no. 3, pp. 213-218, 1996.

[35] G. Vancanneyt, R. Schmidt, A. O'Connor-Sanchez, L. Willmitzer, and M. Rocha-Sosa, "Construction of an introncontaining marker gene: splicing of the intron in transgenic plants and its use in monitoring early events in Agrobacteriummediated plant transformation," Molecular and General Genetics, vol. 220, no. 2, pp. 245-250, 1990.

[36] G. An, P. Ebert, A. Mitra, and S. Ha, "Binary vectors," in Plant Molecular Biology Manual, S. B. Gelvin and R. A. Schilperoort, Eds., pp. 1-19, Kluwer Academic Publishers, Dordrecht, Netherlands, 1988.

[37] J. M. Álvarez, J. Majada, and R. J. Ordás, “An improved micropropagation protocol for maritime pine (Pinus pinaster Ait.) isolated cotyledons," Forestry, vol. 82, no. 2, pp. 175-184, 2009.

[38] B. Bubner and I. T. Baldwin, "Use of real-time PCR for determining copy number and zygosity in transgenic plants," Plant Cell Reports, vol. 23, no. 5, pp. 263-271, 2004.

[39] K. J. Livak and T. D. Schmittgen, "Analysis of relative gene expression data using real-time quantitative PCR and the 2$\Delta \triangle$ CT method," Methods, vol. 25, no. 4, pp. 402-408, 2001.

[40] J. M. Ruijter, C. Ramakers, W. M. H. Hoogaars et al., "Amplification efficiency: linking baseline and bias in the analysis of quantitative PCR data," Nucleic Acids Research, vol. 37, no. 6, p. e45, 2009.

[41] S. M. Reddy, A. K. Pandey, D. Melayah, R. Marmeisse, and G. Gay, "The auxin responsive gene $P p$-C61 is up-regulated in Pinus pinaster roots following inoculation with ectomycorrhizal fungi," Plant, Cell and Environment, vol. 26, no. 5, pp. 681-691, 2003.

[42] R. A. Jefferson, T. A. Kavanagh, and M. W. Bevan, "GUS fusions: beta-glucuronidase as a sensitive and versatile gene fusion marker in higher plants," EMBO Journal, vol. 6, no. 13, pp. 39013907, 1987.

[43] M. M. Bradford, "A rapid and sensitive method for the quantitation of microgram quantities of protein utilizing the principle of protein dye binding," Analytical Biochemistry, vol. 72, no. 1-2, pp. 248-254, 1976.

[44] A. Ramarosandratana, L. Harvengt, A. Bouvet, R. Calvayrac, and M. Pâques, "Effects of carbohydrate source, polyethylene glycol and gellan gum concentration on embryonal-suspensor mass (ESM) proliferation and maturation of maritime pine somatic embryos," In Vitro Cellular and Developmental Biology Plant, vol. 37, no. 1, pp. 29-34, 2001. 
[45] A. Humánez, M. Blasco, C. Brisa, J. Segura, and I. Arrillaga, "Somatic embryogenesis from different tissues of Spanish populations of maritime pine," Plant Cell Tissue Organ Culture, vol. 111, pp. 373-383, 2012.

[46] R. Álvarez, P. Alonso, M. Cortizo et al., "Genetic transformation of selected mature cork oak (Quercus suber L.) trees," Plant Cell Reports, vol. 23, no. 4, pp. 218-223, 2004.

[47] R. Torreblanca, S. Cerezo, E. Palomo-Ríos, J. A. Mercado, and F. Pliego-Alfaro, "Development of a high throughput system for genetic transformation of olive (Olea europaea L.) plants," Plant Cell, Tissue and Organ Culture, vol. 103, no. 1, pp. 61-69, 2010.

[48] E. Corredoira, D. Montenegro, M. San-Jose, A. Vieitez, and A. Ballester, "Agrobacterium-mediated transformation of European chestnut embryogenic cultures," Plant Cell Reports, vol. 23, no. 5, pp. 311-318, 2004.

[49] J. M. Humara, M. López, and R. J. Ordás, “Transient expression of the uidA gene in Pinus pinea cotyledons: a study of heterologous promoter sequences," Plant Cell, Tissue and Organ Culture, vol. 56, no. 2, pp. 69-78, 1999.

[50] R. B. Malabadi, J. A. T. da Silva, and K. Nataraja, "Agrobacterium tumefaciens-mediated genetic transformation of Pinus kesiya Royle ex Gord (Khasi Pine)," Asian and Australasian Journal of Plant Science and Biotechnology, vol. 2, pp. 7-14, 2008.

[51] K. A. Feldmann, “T-DNA insertion mutagenesis In Arabidopsis: mutational spectrum," Plant Journal, vol. 1, no. 1, pp. 71-82, 1991.

[52] R. Alvarez, J. M. Alvarez, J. M. Humara, Á. Revilla, and R. J. Ordás, "Genetic transformation of cork oak (Quercus suber L.) for herbicide resistance," Biotechnology Letters, vol. 31, no. 9, pp. 1477-1483, 2009.

[53] M. Cervera, J. A. Pina, J. Juárez, L. Navarro, and L. Peña, "A broad exploration of a transgenic population of citrus: stability of gene expression and phenotype," Theoretical and Applied Genetics, vol. 100, no. 5, pp. 670-677, 2000.

[54] A. J. M. Matzke and M. A. Matzke, "Position effects and epigenetic silencing of plant transgenes," Current Opinion in Plant Biology, vol. 1, no. 2, pp. 142-148, 1998.

[55] M. Stam, J. N. M. Mol, and J. M. Kooter, "The silence of genes in transgenic plants," Annals of Botany, vol. 79, no. 1, pp. 3-12, 1997. 

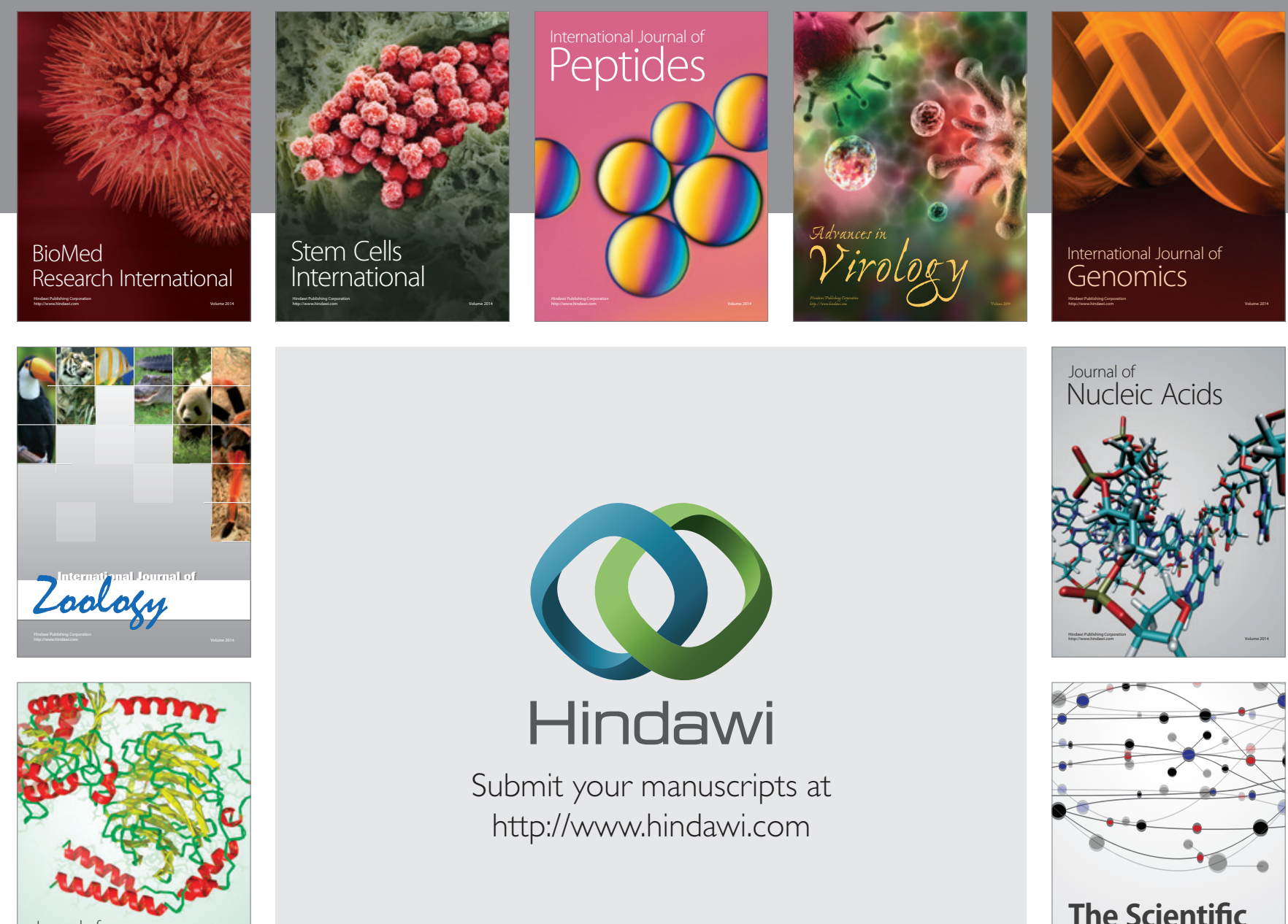

Submit your manuscripts at

http://www.hindawi.com

Journal of
Signal Transduction
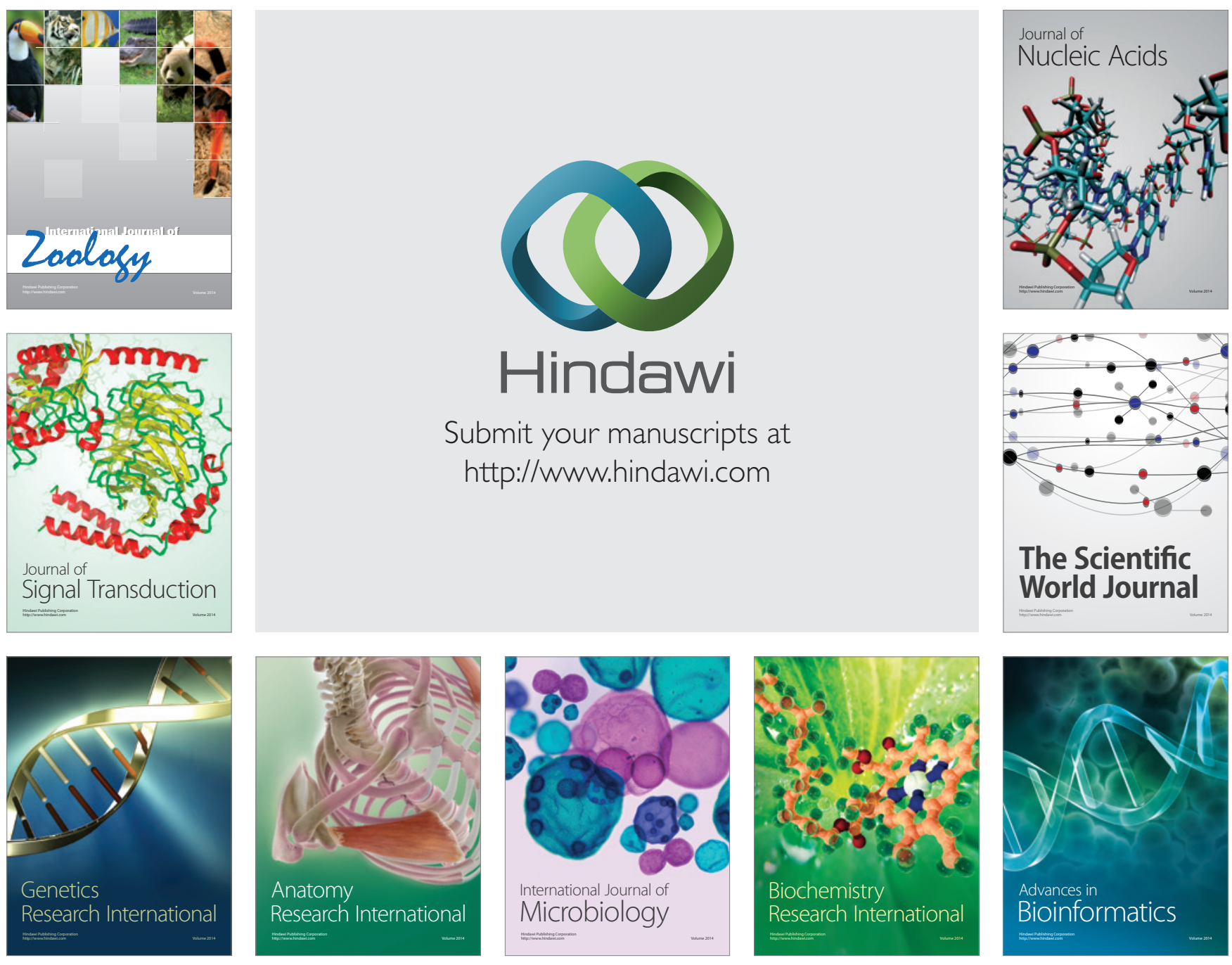

The Scientific World Journal
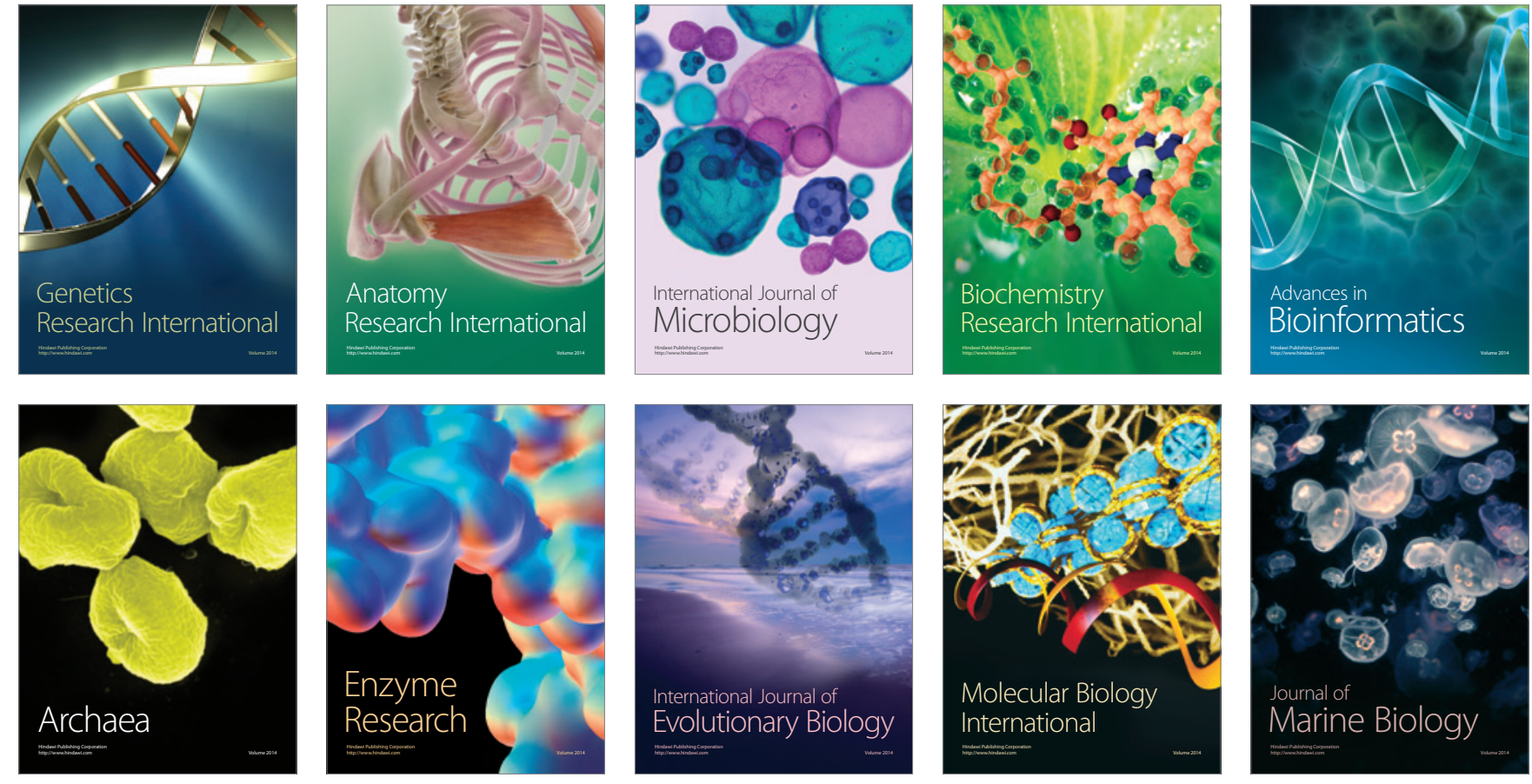